\title{
Redes y paisajes conceptuales en la Evo-Devo*
}

Nets and Conceptual Landscapes in Evo-Devo

Mario Casanueva ${ }^{\dagger \ddagger}$

\section{Resumen}

El texto revisa diferentes estrategias que se han empleado para (i) trazar una línea de demarcación entre la Teoría Sintética de la Evolución y la Biología Evolutiva del Desarrollo (Evo-Devo) y (ii) estructurar la diversidad interna de la Evo-Devo. A continuación, se ilustra, mediante tres ejemplos, la forma en que los sistemas de representación usados en Evo-Devo plasman diferentes supuestos suyos. Finalmente, se discuten las dos principales metáforas con las que se ha pretendido caracterizar la situación actual de la Evo-Devo y se aboga en favor de un enfoque pluralista.

Palabras clave: sistemas de representación - pluralismo epistemológico - pluralismo ontológico - Evo-Devo - teoría sintética de la evolución

\begin{abstract}
Different strategies that have been used to draw a demarcation between the Synthetic Theory of Evolution and Evolutionary Developmental Biology (Evo-Devo) and to structure internal diversity of Evo-Devo are presented. Three examples of how representation systems used in Evo-Devo reflect their assumptions are analyzed. Finally the two main metaphors that have sought to characterize the current situation of Evo-Devo are discussed. The article argues in favor of a pluralistic approach in Philosophy of Evo-Devo.
\end{abstract}

Keywords: systems of representation - epistemological pluralism - ontological pluralism - Evo-Devo - Synthetic Theory of Evolution

\footnotetext{
* Recibido: 10 de Mayo de 2014. Aceptado en versión revisada: 30 de Julio de 2014.

† Departamento de Humanidades, Phibio, REMO, Universidad Autónoma Metropolitana-Cuajimalpa, México. Para contactar al autor, por favor, escriba a: mario.casanueva@gmail.com.

* Estoy en deuda con los todos integrantes de los seminarios Phibio y REMO, en particular con Nuria Valverde, Mariana Peimbert, Ximena González, Octavio Valadez, Max Martínez y Diego Méndez, por haber contribuido con sus ideas a mejorar este trabajo. Este trabajo participa de los proyectos CB 182084, del CONACYT, México, y PICT2007 № 1558 del ANPCyT, Argentina. Metatheoria 5(1)(2014): 83-97. ISSN 1853-2322.

(c) Editorial de la Universidad Nacional de Tres de Febrero. Publicado en la República Argentina.
} 


\section{Fronteras y taxonomías internas de la Evo-Devo}

Durante las dos últimas décadas, la biología, la filosofía de la biología y la historia de la biología, han gestado y mantenido gran interés en la Biología Evolutiva del Desarrollo o Evo-Devo. A diferencia de otros territorios como la genética de poblaciones, la biología molecular (con las ciencias ómicas incluidas), la taxonomía, la fisiología, y otros muchos que pueden ser organizados con base en la naturaleza de sus modelos o aplicaciones pretendidas, la estructura interna de la Evo-Devo y la naturaleza de su contribución al concierto total de la Biología, no resultan nítidas en una primera aproximación. Esto quizá se deba a la ausencia de un corpus teórico-conceptual constituido en torno a leyes, pero debe reconocerse que los diferentes modelos que conforman la Evo-Devo, tomados individualmente, son claros y sus sistemas, mecanismos o modelos están delimitados con precisión (aunque algunos puedan caracterizarse de complejos) adicionalmente la pretendida ausencia de leyes también ocurre en otros campos que no nos resultan tan intrincados. El problema más bien radica en su ensamble, su articulación con el conocimiento de fondo. Los modelos de la Evo-Devo, aunque parcialmente complementarios, son sumamente diversos, lo que dificulta vislumbrar sus distintas relaciones y, por otro lado, no es clara su articulación con el marco dominante previo, la Teoría Sintética de la Evolución (en ocasiones también llamada neodarwinismo, o darwinismo moderno). ${ }^{1}$ Pues, los modelos de la última se encuentran centrados en una visión genético-matemática que nos ha legado una serie de jerarquías, vínculos y constricciones teóricas que no parecen articularse armónicamente con los modelos de la Evo-Devo.

Considerando la enorme pluralidad de enfoques de la Evo-Devo, y la tensión entre ésta y la Teoría Sintética, no es extraño que existan numerosos trabajos dedicados tanto a postular (o identificar) algún tipo de arquitectura epistémica (o si se prefiere concepto-cognitiva), que dé cuenta de la diversidad de recursos programas y proyectos teórico-experimentales reunidos bajo la bandera de la Evo-Devo. Asimismo, al trazado de una demarcación respecto a la perspectiva de la, nacida dominante, aunque nunca hegemónica, aún robusta, y hoy mermada, tradición que arropa a la Teoría Sintética de la Evolución (p.e. Laubichler \& Maienschein 2007, Carroll 2008, Pigliucci \& Müller 2010, Noble 2015).

Los intentos por trazar una línea divisoria entre la Evo-Devo y la Teoría Sintética, han conocido diversas épocas. En una gradación de discrepancia creciente con el statu quo, se ha pasado de pensar a la Evo-Devo como una disciplina en emergencia que provoca tensiones y merece especial atención (p.e. Arthur 2000, Gilbert 2000, 2003a, Raff 2000, Robert 2002, Hall \& Olson 2003, Love \& Raff 2003), a la consideración de la necesidad de una nueva síntesis, donde Evo-Devo y la Teoría Sintética queden integrados (p.e. Callebaut, Müller \& Newman 2007, Müller 2007, Laubichler 2010, Pigliucci \& Müller 2010); a la postulación de la Evo-Devo como enfoque revolucionario que desplaza con ganancia a la Síntesis Evolutiva, con la que está en disfonía, en numerosas notas. Más aún, se sostiene que la última de hecho funge como un obstáculo epistemológico que impide la emergencia de una nueva biología (Laland et al. 2014, Noble 2015).

Por otro lado, los esfuerzos por organizar el campo, han contemplado diferentes estrategias: (i) Algunos (p.e. Raff 2000, Della Pina, Souer \& Koes 2014) ponen el acento en las preguntas planteadas y

\footnotetext{
${ }^{1}$ Aunque a veces, autores como Jablonka y Lamb (2005, 2014), Laubichler (2010) o Noble (2015) así lo hagan. los términos "neodarwinismo" y "teoría sintética" no deberían usarse como sinónimos. Grosso modo, "neodarwinismo" fue un término acuñado hacia principios del siglo XX (radicado en la tradición anglosajona aunque primordialmente europeo) para referir a una versión recortada del pensamiento de Charles Darwin que otorgaba primacía absoluta a la selección natural por sobre otros mecanismos evolutivos de corte lamarckiano (Romanes, Wallace, Weismann, etc.), por su parte, la expresión "Teoría Sintética de la Evolución" o simplemente "Teoría Sintética", "Síntesis Evolutiva" o "Síntesis Moderna" se refiere a la "fusión" de los núcleos "mendeliano" y "darwiniano". Como es sabido, la voz "Síntesis Moderna" fue acuñada por Julian Huxley en los cuarenta del siglo pasado, pero de manera laxa abarcaría a la "fusión" del primer neodarwinismo con la genética de Mendel-Morgan y según algunos incluye desde los trabajos de R.A. Fisher en 1918 hasta los cincuenta y sesenta. R.A. Fisher, Theodosius Dobzhansky, J.B.S. Haldane, Sewall Wright, William Donald Hamilton, Cyril Darlington, Julian Huxley, Ernst Mayr, George Gaylord Simpson y G. Ledyard Stebbins fueron algunos de sus destacados representantes. Lo que de manera mucho más reciente Jablonka y Lamb, Laubichler, Noble y algunos más buscan referir cuando emplean la expresión "neodarwinismo" es a una visión de la evolución centrada en los genes, con la mutación como principal mecanismo de variación. Tal visión iría mucho más allá de la Teoría Sintética de la Evolución original, pues, entre otros, la genética no se limita a la cromosómica, se añade una perspectiva molecular, se acepta la pertinencia de varios niveles de selección tanto hacia abajo como hacia arriba y se postulan varios tipos de jerarquías biológicas, pero ello excede a los límites de este ensayo.
} 
los retos a enfrentar en un futuro cercano. Considérese, por ejemplo, la siguiente lista: ¿cómo se originan y evolucionan los distintos sistemas y redes de regulación genética que participan del control de las secuencias de desarrollo de los fenotipos?, ¿qué función tienen los módulos en el desarrollo y la evolución?, ¿cómo y de qué manera las restricciones impuestas por la articulación de los procesos de desarrollo sesgan o canalizan la dirección de los cambios morfológicos durante la evolución?, ¿cómo surgen las novedades morfológicas?, ¿cuál es la relación entre micro-evolución y macro-evolución?, etc. Por ponerlo en términos coloquiales, las primeras de estas preguntas son más Devo en tanto que las últimas son más Evo, sin que exista una línea tajante entre ellas. (ii) Para otros (p.e. Hall 2003 o Hendrikse, Parsons \& Hallgrímsson 2007) la diferencia entre las posiciones incluidas en la Evo-Devo se explica por el énfasis puesto en determinados conceptos y constelaciones de conceptos: "paidomorfismo", "heterocronía”, "modularidad", "innovación", "plan corporal", "constricciones y canalizaciones", "paisaje epigenético", "morfoespacio", "evolucionabilidad” "auto-organización”, etc. Habitualmente, estos conceptos no forman parte de las explicaciones y modelos contemplados por la Teoría Sintética y entre sus frecuencias de uso pueden notarse cambios temporales, de manera que determinadas épocas están caracterizadas por diferentes paisajes conceptuales. (iii) Otros más otorgan primacía a la importancia relativa de los principales mecanismos causales generadores de las formas orgánicas: selección natural, interacción epigenética, plasticidad fenotípica y asimilación genética, y construcción de nicho, entre otros (p.e. Odling-Smee, Laland \& Feldman 2003, Laland, Odling-Smee \& Gilbert 2008, Pigliucci 2009, Jablonka \& Lamb 2005/2014, Minelli \& Baedke 2014, etc.).' (iv) Hay quienes centran su atención en los patrones causales: funcionalidad, mecanicismo, cadenas causales, causalidad descendente o multinivel (p.e. Amundson 2005, Brigandt 2007, Plutynski 2008, Laland et al. 2011, Fischer \& Smith 2012, Kitchen \& Allaby 2013, Casanueva \& Martínez 2014, Martínez \& Esposito 2014). (v) También se ha señalado que la estructura del campo se determina en función de las tradiciones epistémicas y los estilos científico-experimentales involucrados (Winther 2015, Love 2015a). Y, (vi) por último, existen análisis que organizan el campo con base en los principales programas de investigación (Müller 2007, 2014, Gerson 2015, Love 2015a). Aquí destaca en particular la distinción de Gerd Müller del 2007, dada la importancia que ha adquirido conviene describirla, aunque sea ligeramente.

(i) El programa de la embriología y morfología comparada, estudia la diacronía de la morfogénesis, contrastando los detalles de la variación anatómica a lo largo de la diversidad fenotípica, distinguiendo entre patrones de desarrollo primitivos y derivados. Recientemente, ha caracterizado el cambio evolutivo mediante la demarcación de regiones dentro de un morfoespacio fenotípico y para definir trayectorias apela a fenómenos dinámicos como la heterocronía.

(ii) El programa de la genética evolutiva del desarrollo, quizá el más exitoso de la Evo-Devo, estudia la evolución de los sistemas genéticos que regulan el desarrollo, por ejemplo, el diseño y las jerarquías de las redes de regulación genética y las vías de señalización, la mutación, duplicación y divergencia de los genes reguladores, sus patrones de expresión y su papel en la construcción de los planes de desarrollo corporal. Sus principales herramientas han sido la identificación y clonación de genes reguladores (el estudio de las grandes homologías genéticas) y las nuevas técnicas de mapeo genómico y visualización de genes y proteínas en momentos específicos del desarrollo.

(iii) El programa de epigenética experimental, indaga la dinámica de las interacciones moleculares, celulares y tisulares en el desarrollo embrionario a lo largo de la evolución. Explora la subdeterminación genética del fenotipo, destacando la aportación del medio ambiente como factor causal en el desarrollo, atendiendo a los rasgos que no están

\footnotetext{
${ }^{2}$ Si bien se concede un papel creativo y no simplemente eliminativo a la selección natural (como en Darwin, los rasgos adaptativos se construyen paso a paso a lo largo de muchas generaciones, seleccionando las variantes más adaptadas a ambientes locales, en virtud de la comparativamente mayor eficiencia reproductiva que les confieren sus más eficientes rasgos), se considera que otras fuerzas evolutivas también poseen importancia e incluso pueden superar a la selección.
} 
directamente fijados por la expresión de los genes como la auto-organización, los patrones geométricos, o físicos (p.e., orientación en el campo gravitacional, temperatura o tensegridad), o de herencia materna.

(iv) Finalmente el programa teórico y computacional. Está dirigido a las metrizaciones, modelizaciones y simulaciones de la evolución de los sistemas del desarrollo. Entre sus principales actividades se encuentra la precisa determinación de los cambios celulares, tisulares y morfológicos que ocurren al alterar la pauta topológica o temporal de la actividad de los genes. Nuevas herramientas matemáticas y computacionales, han permitido el desarrollo de simulaciones 4D de la expresión génica, en particular modelos para el desarrollo de órganos y sistemas particulares. Este programa ha obtenido avances al mostrarnos cómo las redes emergentes surgidas por autoorganización tienden a ser reemplazadas por redes jerárquicas de regulación genética.

La lista que hemos presentado tanto sobre las propuestas de demarcación entre la Evo-Devo y la Síntesis Evolutiva como de estructuración de la propia Evo-Devo, es meramente ilustrativa (se presenta con la sola intención de destacar la pluralidad de propuestas) y aún podría extenderse en demasía, más si se atienden simultáneamente otras variables como el tipo de organismo modelo involucrado (p.e. Gilbert 2009). ${ }^{3}$

\section{Un breve vistazo a los sistemas de representación}

Tradicionalmente, el ejercicio filosófico sobre el conocimiento ha estado más dedicado al análisis de sus aspectos conceptuales o al estudio etnográfico de sus prácticas. A continuación ensayaré una vía distinta, complementaria a éstas, que atiende más a la naturaleza de los sistemas de representación de los diversos mecanismos y procesos involucrados en la Evo-Devo. En ciencia, imágenes y diagramas pueden ser vistos como modelos teóricos que, al indicarnos el proceder de los sistemas bajo estudio, de manera indirecta (a veces no tan indirecta), nos señalan la ontología y las leyes postuladas por las teorías en cuestión. Esto es, nos dicen qué es lo hay y cómo se comporta en múltiples ocasiones y constituyen herramientas de cálculo que, en virtud de su gran capacidad para la evocación heurística, son apoyos o andamiajes (affordances) útiles y hasta estratégicos para la obtención de inferencias. ${ }^{4} \mathrm{~A}$ continuación se consideran unos pocos ejemplos de fotografías, diagramas e imágenes, con la sola intención de ilustrar su diversidad y, en algunos casos, contrastar la visión de la Evo-Devo con la visión de la embriología clásica y la evolución acorde a las propuestas de la Teoría Sintética.

Un primer tipo de imágenes que deseo considerar aquí, ocurren en el contexto de la embriología tradicional y aunque no está claramente situada dentro de la Evo-Devo mantiene relaciones con ésta, pues sin Devo no hay Evo-Devo. Me refiero a las imágenes de divulgación que muestran los cambios macroscópicos temporales en el desarrollo de un organismo (por ejemplo, el pollo o el humano) medidos en días o semanas. Su tradición es muy antigua y se retrotrae a Aristóteles o, de manera moderna, a Malpighi. Tres extraordinarios ejemplos pueden verse en Polutry (2006), Mormino (2011) y Leung (2004). Como tempranamente señalaron Hamburger y Hamilton (1951), en su clásica monografía sobre el desarrollo del pollo, el método es totalmente arbitrario. No hay por qué esperar que los bioprocesos involucrados en el desarrollo sigan el patrón de las revoluciones de nuestro planeta en

\footnotetext{
${ }^{3}$ En términos generales, en el campo de la Evo-Devo, pueden señalarse ocho organismos modelo básicos, siete de ellos animales: el erizo púrpura (Strongylocentrotus purpuratus), la mosca de la fruta (Drosophila melanogaster), un nematodo rabdítido de climas templados (Caenorhabditis elegans), el ratón casero (Mus musculis), la rana africana de uñas con sus grandes ovocitos y embriones (Xenopus laevis), el pez cebra, cyprinio tropical de grandes capacidades regenerativas (Danio rerio), y el pollo común (Gallus gallus), y sólo una planta, una mostaza europea (Arabidopsis thaliana).

${ }^{4}$ En filosofía, la tradición que cultiva el análisis, uso y desarrollo de diagramas útiles al cálculo y obtención de inferencias se remite, cuando menos, a Euclides e incluye personajes tan destacados como Lull, Leibniz o Peirce. En fechas recientes, la Historia y la Filosofía de la Ciencia han realizado un considerable esfuerzo por entender y analizar las imágenes científicas, por captar su uso y su significado, y extraerlas del terreno de lo puramente ornamental, accesorio o incluso anecdótico.
} 
torno a su propio eje, o de la organización laboral e institucional de los humanos. ${ }^{5}$ Sin embargo, la medición de los eventos macroscópicos en días conserva su encanto, pues la refiere a un patrón que nos es más conocido que, por ejemplo, el tiempo de aparición de un determinado número de somitas. Además, puede seguirse fácilmente en un salón de clase, donde el embrión de pollo es una extraordinaria herramienta educativa que ayuda a moldear nuestra comprensión de la embriología de vertebrados.

A pesar de que estas observaciones son macroscópicas, no se piense que por ello son poco sofisticadas o ingenuas. Tanto las ilustraciones anatómicas de Elsie Herbold Froeschner, que enriquecen la monografía de Hamburger y Hamilton, como las fotografías digitales de la cámara de agua de Michelle Leung (2004), por citar sólo dos ejemplos, están realizadas por un ojo entrenado que sabe qué observar y cómo destacarlo. Por ejemplo, respecto de sus imágenes, Leung nos advierte sobre la elección del fondo, la iluminación lateral y el manejo digital del contraste, para resaltar los detalles, o la importancia de la cámara de agua para evitar el colapso de las cavidades embrionarias y eliminar reflejos.

Este tipo de imágenes han permanecido con relativamente pocos cambios a lo largo de siglos, la secuencia de las estructuras que van apareciendo en un embrión de pollo a lo largo de sus diferentes etapas de desarrollo admitirían descripciones muy similares acerca de qué partes del embrión se forman antes o después de qué otras, sin embargo, los contextos que dan sentido global a esas preguntas son muy distintos. Ante ellas, Aristóteles quizá se hubiese preguntado algo parecido a "¿cómo se actualizan las potencialidades de la entelequia del pollo en la generación de las partes dentro de un huevo?", en tanto que alguien como Eric H. Davidson quizá se pregunte: “cómo se originan y evolucionan los distintas redes de regulación genética que participan del control de las secuencias de desarrollo del fenotipo en los deuterostomados?".

Nuestro segundo tipo de imágenes están asociadas a la diversidad que se presenta al interior de una especie o un género. Un ejemplo clásico, pre Evo-Devo, lo constituyen las ilustraciones de Edith Wallace sobre variaciones fenotípicas de Drosophila (Caltech Archives 2009/2011), que en el contexto de la Teoría Cromosómica de la Herencia acompañaron a los trabajos del grupo Drosophila (Fly Room) liderado por Thomas H. Morgan, en el California Institute of Technology. Los dibujos de E. Wallace incorporan un extraordinario detalle e información bibliográfica (al margen de sus imágenes ella anotaba el tipo y la fuente de la mutación, si el portador era macho o hembra y las iniciales de quien había encargado la ilustración), ${ }^{6} \mathrm{y}$ al igual que las ilustraciones monográficas de muchos herbarios o laboratorios de entomología, en ocasiones son más útiles que una fotografía, pues construyen a su objeto relevando o destacando determinadas partes que no siempre son claramente visibles en el espécimen biológico. A más de ochenta años de distancia, los dibujos de E. Wallace sobre la diversidad fenotípica de la mosca de la fruta, pueden contrastarse con las fotografías (10X) de series de alas escindidas del cuerpo, que aparecen en algunos estudios claramente Evo-Devo, sobre la evolución de los patrones de pigmentación alar en Drosophila de Prud'homme (2013). En éstas, la información del texto que las acompaña hace referencia a redes de regulación genética, efectos pleiotrópicos, coevolución de rasgos morfológicos y conductuales, variación fenotípica inter e intra especies,

\footnotetext{
${ }^{5}$ La falta de correlación entre la edad cronológica (basada en un tiempo universal estandarizado) y la estructural es amplia y posee orígenes variados, diferencias genéticas (v.g., un embrión de la raza White Leghorn se desarrolla más rápidamente que uno de la raza Barred Plymouth Rock) diferencias estacionales, viabilidad y vigor de los embriones, tiempo que tardan en llegar a la incubadora, tamaño de los huevos, temperatura de incubación etc. (Hamburger \& Hamilton 1951). En los procesos de desarrollo (como en el resto de los bioprocesos) conviene no perder de vista que muchas veces la propia pauta de los devenires biológicos constituye una mejor escala para la metrización que la referencia a un tiempo universal estandarizado. En este caso, la referencia a los estados de desarrollo, más que a una cronología alienante, permite estandarizar sus diferentes fases y dar seguimiento a la secuencia en la que los diferentes caracteres se tornan prominentes, lo que ayuda al diagnóstico.

6 Los trabajos de E. Wallace, aparecen en textos que incluyen, por ejemplo, información sobre las frecuencias de recombinación con otras variantes genéticas y la inferencia a partir de ello de la posición cromosómica relativa del gen responsable de tal o cual variante fenotípica (Morgan 1917, Sturtevant 1921).
} 
relaciones filogenéticas entre patrones de pigmentación, comparación entre patrones evolutivos de diversos órdenes, etc. (Pick \& Heffer 2012, Arnoult et al. 2013, Prud'homme et al. 2011). ${ }^{?}$

Las imágenes de E. Wallace y las de Prud'homme y asociados pueden considerarse bastante similares, sus descripciones comparten elementos, aunque presentan diferencias patentes y el contexto conceptual en el que ocurren es notoriamente diferente. Esto no es inusual, algo similar ocurre con, por ejemplo, las imágenes de los mapas de destino celular (fate maps). Las publicadas hace más de un siglo, por Edwin G. Conklin, sobre el destino final de los linajes celulares (con sus posiciones y proporciones definitivas) del cigoto de Ascidia (un tunicado) son uno de lo más preclaros ejemplos de anatomía descriptiva e ilustración embriológica (Conklin 1905), ${ }^{8}$ y tienen su correlato moderno en los mapas de destino de Oikopleura dioica (otro tunicado) (Fujii, Nishio \& Nishida 2008, Nishida 2008). Nuevamente, las imágenes son muy similares, sus descripciones conservan numerosos elementos en común, aunque presentan diferencias claras, mas su contexto es muy diferente, los trabajos del siglo XXI hacen gala de una tecnología y conocimientos no vislumbrados a principio del siglo XX (por ejemplo, el señalamiento de que mRNAs maternos desempeñan papeles críticos en la determinación del destino celular, la activación de genes homeóticos y de vías de señalización, o el uso de técnicas como la microscopía de contrastaste de interferencia diferencial o la microscopía confocal fluorescente).

Un último tipo de imágenes al que deseo refirme no encuentra parangón en etapas previas a la moderna caracterización de la Evo-Devo, ${ }^{9}$ se trata de ilustraciones, diagramas o fotografías que correlacionan varios parámetros, pudiendo faltar algunos de ellos. Árboles filogenéticos, en los que se señalan taxones evolutivamente distantes, se correlacionan con las respectivas presencias de genes Hox y las correspondientes regiones embrionarias o del cuerpo adulto en donde se expresan. Véase, por ejemplo, la figura 1.

La imagen de la figura uno destaca profundas y antiguas homologías genéticas entre los deuterostomados, a pesar de los cambios en su muy amplia diversidad de planes corporales (los hay de simetría, radial o bilateral o cambiante a lo largo de su desarrollo; con o sin formas larvarias de vida independiente, solitarios o coloniales, con o sin eje dorsal ventral, etc.). Un grupo relativamente pequeño de genes homeóticos, que poseen una organización cromosómica colineal, controla la regionalización corporal. El patrón de las secuencias génicas presente arroja luz sobre las relaciones filogenéticas de los deuterostomados.

\footnotetext{
7 Aunque esta sección está dedicada al análisis de imágenes, cabe señalar que no existen imágenes auto-identificantes: para saber cómo juzgar una imagen, es necesario apoyarse en el texto donde ésta aparece, a fin de identificar con claridad de qué se está hablando. Al igual que con un texto, considerar su contexto es necesario para una adecuada interpretación.

8 Las ilustraciones de Conklin se reproducen en el libro y página web de Gilbert (2013).

9 Si bien la mancuerna evolución-desarrollo puede remontarse al siglo XIX (Love \& Raff 2003, Hoßfeld \& Olsson 2003, Laubichler \& Maienschein 2007, Love 2015b), en torno a los orígenes de la Evo-Devo contemporánea se han señalado varios hitos (Hall 2003), la publicación de Embryos and Ancestors (de Beer 1940) o más tarde de Ontogeny and Phylogeny (Gould 1977), destacaron la importancia del paidomorfismo y a la heterocronía como mecanismo evolutivo; el descubrimiento de los genes homeóticos (Lewis 1978, Gehring 1985), y su identificación como genes altamente conservadores que regionalizan el cuerpo a lo largo del eje anterior a posterior (de la cabeza a la cola) del embrión (genes Hox); los trabajos sobre los orígenes de la pluricelularidad en mixomicetos (Bonner 1955); la Conferencia Dahlem sobre "Evolución y Desarrollo", realizada en Berlín en 1981, etc. (Bonner 1982, Hall 2003).
} 


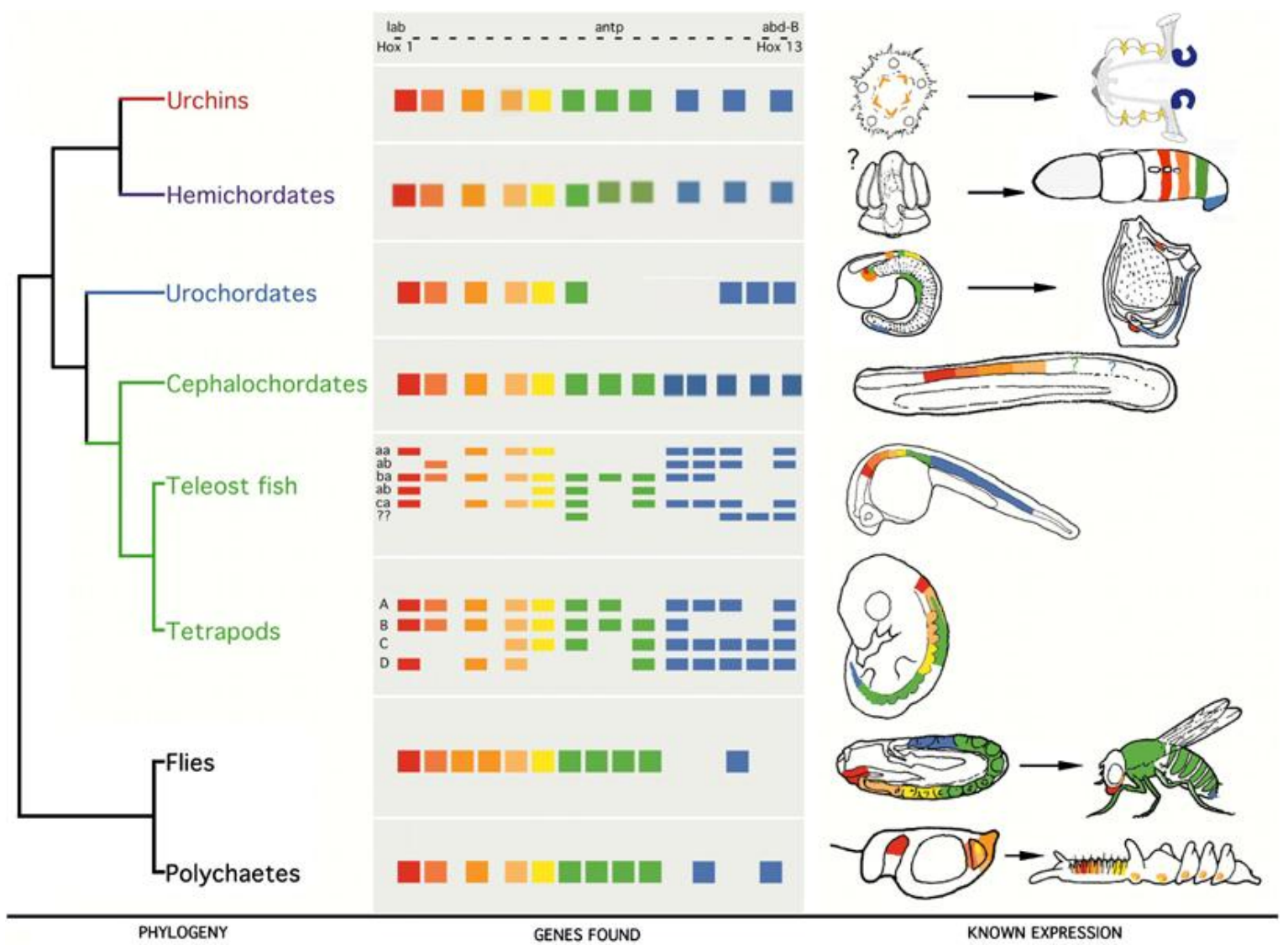

Figura 1. La expresión de los genes Hox en deuterostomados. Hay ocho juegos de genes Hox en peces teleósteos, lo que muestra una duplicación adicional de los cuatro juegos que se encuentran en los vertebrados tetrápodos. En contraste, los deuterostomados invertebrados tienen cada uno un único juego. Las ascidias carecen de algunos de los genes Hox medios, y el grupo se divide en dos cromosomas. Equinodermos y hemicordados comparten una duplicación independiente de los genes posteriores, llamados Hox $11 / 13 \mathrm{a}$, Hox $11 / 13 \mathrm{~b}$ y Hox $11 / 13 \mathrm{c}$. Los hemicordados expresan una orientación anterior a la posterior en el ectodermo, que más adelante, durante el desarrollo, producirá una red de nervios. Los Equinodermos adultos expresan el anillo nervioso en el lado oral, en lo que corresponde a la posición anterior en cordados y hemicordados. Tomada de Swalla (2006).

Las imágenes de este tipo constituyen las ilustraciones emblemáticas de Evo-Devo, pues compendian sus dos cuestiones básicas: cómo han evolucionado los sistemas de desarrollo y cómo los cambios en los sistemas de desarrollo pueden afectar las trayectorias evolutivas. Por otro lado, muestran la magnitud de la evolución de la que se está hablando. En ellas la macroevolución se muestra en todo su esplendor y no es más una mera extrapolación de procesos microevolutivos. En la iconografía tradicional de la evolución, con exclusión de los diagramas arbóreos de la genealogía de las especies (como el cono de diversidad creciente de Darwin, o los fabulosos pedigríes de Haeckel), e ilustraciones de la ley biogenética (aunque sean un artefacto), muy frecuentemente, la evolución era (y, en muchos casos, continúa siendo) representada como series de cambios graduales en un solo linaje filético. Las imágenes de la evolución del caballo como una serie que inicia con el Eohippus y contiene una progresión de especies que incrementan su tamaño, de manera concomitante a la disminución del número de dedos, hasta llegar al caballo moderno de gran tamaño y con un solo dedo en la pesuña, o las de una sucesión de homínidos que van incrementando su estatura y posición erecta desde el Australopithecus hasta el Homo sapiens, se constituyeron en íconos de la evolución orgánica. Tales imágenes tienen un pequeño recorrido en el morfoespacio. En contrario, imágenes del tipo de la figura uno tienen un recorrido amplio, en ellas, la evolución no se concibe en términos de pequeños cambios que se acumulan a lo largo del tiempo. Los cambios graduales extrapolados en el tiempo o en el espacio (como en la evolución de las especies anillo, donde una serie de poblaciones que cambian gradualmente en torno a una zona de hábitat inadecuado termina por generar dos tipos distintos que coexisten sin cruzarse), son sustituidos por imágenes que contienen grandes cambios fenotípicos. Al 
comparar los sistemas de representación de la Evo-Devo con aquellos que, para hablar de la evolución y el desarrollo, ofrece la Teoría Sintética (traducción casi directa de genotipos (genes o grupos de genes) a fenotipos, prendido y apagado de genes en diferentes momentos, especiación alopátrica, simpátrica o parapátrica, barreras geográficas y especies anillo, seguimiento de picos adaptativos, etc.), es claro que no se está hablando de los mismos procesos, en tanto modelos, estos sistemas de representación reflejan diferentes compromisos ontológicos, p.e., en la Evo-Devo, la evolución no se piensa tanto en términos de cambios en las frecuencias génicas, sino como procesos de surgimiento de bioformas.

En esta sección, se ha presentado, a grandes saltos, una serie de imágenes que van desde aquellas que se encuentran en los límites de la Evo-Devo y mantienen una clara continuidad con imágenes previas, hasta aquellas centrales a la Evo-Devo y que no poseen un claro parangón con imágenes previas, entre ambos tipos existen otras imágenes que poseen tanto semejanzas como diferencias con las anteriores. A lo largo de la serie hay una cierta continuidad que liga sus elementos y también cabe destacar una tendencia temporal a incrementar tanto la variedad de sistemas de representación como los nexos entre los diferentes sistemas.

\section{Redes de representaciones}

Los procesos de la ontogénesis pueden examinarse a distintos niveles de organización (molecular, subcelular, celular, tisular, etc.) y dentro de cada uno pueden emplearse diversos descriptores. Por ejemplo, en el nivel molecular la embriogénesis puede ser vista como el comportamiento dinámico de una red de regulación genética espacio-temporalmente distribuida (Saudemont et al. 2010, Longabaugh 2012), pero igualmente como una sucesión de vías de señalización también regional y temporalmente distribuida; componentes como Notch, Hedgehog, diversas proteínas morfogenéticas óseas y factores de crecimiento epidérmico, entre otros, organizan y regulan la formación de morfógenos y generan cascadas de transcripción que forman parte de la lógica de la regulación del desarrollo (Gazave et al. 2009, Sethi et al. 2012). Las interacciones entre las redes de regulación y las vías de señalización generan fenómenos emergentes que forman parte del paisaje de regulación (regulatory landscape) (Annunziata et al. 2014). Más allá de los procesos de regulación, el metaboloma del embrión también admite descripciones espacio temporales que caracterizan su estado de salud y desarrollo (Sakkas, KatzJaffe \& Sueldo 2014, Krisher, Schoolcraft \& Katz-Jaffe 2015). Por su parte, en el nivel subcelular, la embriogénesis podría ser representada como un mapa dinámico de las diferentes regiones cromosómicas que se encuentran activas en los distintos linajes celulares (Bianchi-Frias et al. 2004, Filion et al. 2010), y de igual manera los microtúbulos, organelos membranosos y mitocondrias, entre otros, presentan una génesis y distribución diferencial a lo largo de las etapas y los linajes celulares durante el desarrollo (Maro, Johnson \& Pickering 1985, Houliston, Pickering \& Maro 1987, Bavister $\&$ Squirrell 2000). En el nivel celular, también pueden usarse varios tipos de caracterizaciones para dar cuenta de los procesos de diferenciación local y la misma pluralidad descriptiva se observa en niveles supra celulares.

Las entidades vivas poseen tanto genidentidad (i.e., son susceptibles de cambio sin pérdida de identidad, p.e., aunque fuimos ese o aquel bebé, ya no lo somos) como pluralidad epistemo-ontológica (i.e., admiten múltiples caracterizaciones teóricas sin que ninguna de ellas posea, en principio, una primacia sobre las demás; Weiss 1950, von Bertalanffy 1972, Emmeche, Køppe \& Stjernfelt 1997, Noble 2006, entre otros) y cada una de estas caracterizaciones postula una determinada ontología. Son nuestras teorías quienes nos dicen qué clase de cosas hay en el mundo (Putnam 1981, Moulines 1994). ${ }^{10}$

Los seres vivos y sus procesos (embriogénesis, reproducción, especiación, sucesión ecológica, etc.) están inmersos en una red que abarca un amplio rango de niveles de organización, con muy diferentes

\footnotetext{
${ }^{10}$ Solo por decirlo al paso, en ciencia, no hay ontología al margen de alguna teoría y no hay teoría sin ontología; el compromiso ontológico implícito en la enunciación de los modelos de la teoría va más allá de nuestra intención de salvar las apariencias, pues dichos modelos contienen postulados de existencia sin los cuales el cálculo interno a la teoría carece de sentido.
} 
tipos de relaciones: simultaneidad, sucesión, asignación, inducción, implicación, determinación, etc. Su pluralismo epistemo-ontológico, descansa en estas relaciones. En torno a ellas, se teje una compleja urdimbre de modelos y sistemas de representación entre los cuales también existen relaciones diversas (ver figura 2).

Niveles de organización

moléculas organelos células tejidos organismo

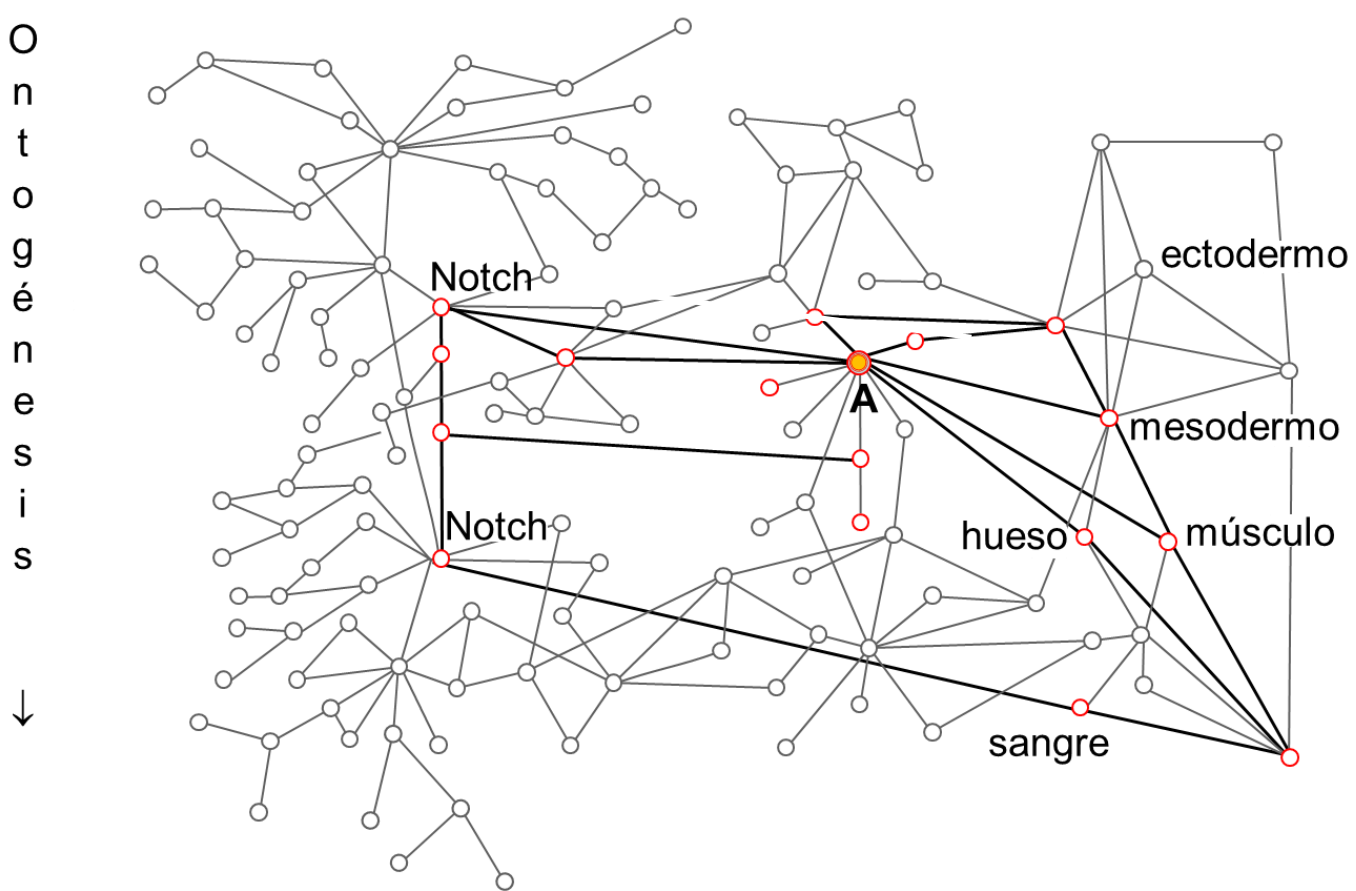

Figura 2. Ejemplo de una porción de una red multinivel. Una célula (A) del mesodermo, interactúa con las células vecinas. Dicha célula, surgió de células del ectodermo y dará lugar a parte del músculo y del esqueleto de la pata de un gato. La célula del mesodermo va a migrar y sólo después de esto va a expresar de forma oscilatoria varios grupos de genes, incluida la vía de señalización Notch (proteína receptora involucrada también en la génesis del tejido sanguíneo del adulto). Tomada de Casanueva, Folguera y Peimbert (2013), ligeramente modificada.

El conjunto no conforma un sistema perfectamente organizado e internamente consistente, sino una trama más o menos laxa donde algunas regiones, pueden entrar en tensión o conflicto con otras y se admiten principios locales de racionalidad. A diferencia de una jerarquía simple, en la red cada par de nodos puede relacionarse por más de una ruta, y adicionalmente no todas las descripciones se actualizan en un determinado momento. Es decir, no todos los sistemas de representación se utilizan al mismo tiempo, pasamos de unos a otros en función de nuestra utilidad o conveniencia (Casanueva, Folguera \& Peimbert 2013). Para decirlo nuevamente en los muy conocidos y más ilustrativos términos de Otto Neurath:

Somos como navegantes que tienen que transformar su nave en pleno mar, sin jamás poder desmantelarla en un dique de carena y reconstruirla con los mejores materiales. Sólo los elementos metafísicos pueden eliminarse sin dejar huella. De un modo u otro quedan conglomerados lingüísticos imprecisos como componentes de la nave. Si bien podemos disminuir la imprecisión en un sitio esta puede surgir acrecentadamente en otro (Neurath 1932).

\section{Las metáforas del cambio conceptual}


La pregunta sobre si la incorporación de la Evo-Devo al marco de la Teoría Sintética de la Evolución requiere de una síntesis ampliada o de una revolución permea la literatura desde hace más de una década (Arthur 2000, Gilbert 2000, 2003a, 2003b, Raff 2000, Robert 2002, Love \& Raff 2003). Como vimos, las posturas se han ido radicalizando paulatinamente distinguiéndose básicamente tres posiciones: (i) aquí no pasa nada que no haya pasado ya, en otras ocasiones, se trata del desarrollo normal de una teoría donde los problemas de extensión y articulación producen cambios más o menos grandes que pueden ser coherentemente asimilados al corpus teórico principal vigente en el momento (ver la posición de Wray, Hoekstra, Futuyma, Lenski, Mackay, Schluter \& Strassmann en Laland et al. 2014); (ii) se requiere una modificación o extensión significativa en la estructura de la teoría evolutiva, la llamada Síntesis Evolutiva Extendida, que integre un nuevo núcleo fundamental (p.e. Noble 2015); y (iii) se requiere una revolución, la Teoría Sintética de la Evolución debe ser abandonada, pues constituye un obstáculo epistemológico (ver la posición de Laland, Uller, Feldman, Sterelny, Müller, Moczek, Jablonka \& Odling-Sme en Laland et al. 2014).

Para los partidarios del "todo está bien" (Wray, Hoekstra, Futuyma, Lenski, Mackay, Schluter \& Strassmann en Laland et al. 2014) los ruidos revolucionarios son un efecto propagandístico. La teoría se ajustará a los nuevos datos como lo ha hecho en el pasado (la identificación de las bases materiales de la herencia, la evolución neutral, la ampliación del número de niveles en los que actúa la selección, la selección de parentesco, etc.) y cuenta con los recursos para ello. Los partidarios de la ampliación son reformistas y saben que se deberán abandonar algunos conceptos (p.e., herencia exclusivamente genética o selección mononivel), pero piensan que el ajuste es posible y podemos continuar bajo un solo marco. Los demandantes del cambio piensan que los puntos en pugna hacen insalvable la continuidad. Aunque no emplean un vocabulario Kuhniano, tienen en mente un cambio de paradigma. Lo que está en juicio es el tipo y magnitud relativa de las fuerzas evolutivas y todos los recursos cognitivos relevantes están sobre la mesa, incluso la supremacía rectora de la Selección Natural (el "centro" neodarwiniano) o el mapeo genotipo $\rightarrow$ fenotipo enfocado en los genes (el "centro" mendeliano). ${ }^{11}$ En su lucha, los revolucionarios han sabido sumar posiciones y a las voces originadas en la Evo-Devo se han juntado otras provenientes principalmente de terrenos asociados a la Teoría de la Construcción de Nicho, al microbioma y al holobionte, que también demandan grandes cambios en la ontología subyacente a la arquitectura general de la biología.

Antes de decantarnos por alguna posición cabe preguntarse si las tres enunciadas agotan las posibilidades. La respuesta es clara: no. Todas comparten un prejuicio pues, de alguna manera, juzgan como positiva la existencia de una hegemonía teórica. Quienes propugnan por la continuidad del marco clásico de la Teoría Sintética, desean conservar dicha hegemonía; los partidarios de la extensión esperan una subsunción correctiva; ${ }^{12}$ y los, cada vez más, partidarios de una revolución desean el reemplazo de una posición hegemónica por otra.

Quizá, las metáforas adecuadas no están en juego. Si se abandona la pretensión de la hegemonía, pueden surgir otras imágenes. Por ejemplo, una que contenga la imagen de un pluralismo o una alternancia de modelos. Especialmente atractivo podría ser un pluralismo de entidades tecnoconceptuales engarzadas en una (¿o varias?) red(es) dinámica(s) de relaciones de inferencia y de actuación (Casanueva 2010). En ella(s) habría regiones local y temporalmente más robustas que otras, pero ninguna tendría permanencia asegurada. Aunque en términos generales y globalmente considerada es de suponerse una cierta continuidad o transformación coherente de elementos que permita dar cuenta de la pretensión de todos ellos de versar sobre la vida.

Las metáforas con las que conceptuamos los fenómenos guían nuestras acciones y representaciones (Lakoff \& Johnson 1980/2003, 1999, Lakoff \& Nuñez 2000) y es claro que han impactado el curso de la biología, (p.e. Keller 2000, 2002). Una metáfora, más que sólo una manera de hablar, también lo es de pensar y hacer, nuestro lenguaje no sólo es descriptivo también es performativo. La historia de la biología campea en ejemplos, desde individuos particulares, hasta culturas completas. Pensemos, por

\footnotetext{
${ }^{11}$ No uso el término "núcleo" por no invocar el modelo lakatosiano, pero sí estoy pensando que la idea de que hay algunos conceptos más prescindibles que otros es una buena imagen de la situación.

${ }^{12}$ Aquí el modelo es de corte popperiano: la nueva teoría incluye -corrigiéndola- una porción de la anterior.
} 
ejemplo, en cómo la imagen darwiniana del árbol de la vida como un cono de diversidad creciente, y sus consideraciones acerca de la naturaleza de los fósiles de cuerpo blando, guiaron las reconstrucciones de Walcott, al punto de llevarlo a encajar toda la diversidad de la fauna de Burgess Shale con sus más de veinte clases de artrópodos en unas cuantas clases que corresponden a las formas primitivas de formas actuales (Gould 1990). Involucrando un número mayor de personas, y aunque no para todo mundo y en particular no para Haldane, Fisher o Wright, las exposiciones de la genética de poblaciones fueron criticadas por Mayr por ser demasiado simplistas y soslayar la relevancia de fenómenos como la vinculación, la dominancia o la epistasis que no encajaban de manera inmediata con la imagen de la genética del costal de frijoles (Mayr 1959, Crow 2008). Apenas hace falta mencionar cómo la idea de tipos dominó el pensamiento sobre las especies, durante siglos.

Otra sería la historia de la academia, si las discusiones no se pensaran en términos de metáforas bélicas (una discusión es una lucha), o no se llamase a los adversarios a trabajar más y polemizar menos. Hoy vale la pena romper una lanza en favor del pluralismo en biología y abandonar la exclusividad de las metáforas del cambio científico que postulan la primacía hegemónica de algún modelo por sobre los otros. Si permitimos que solo ellas guíen nuestra forma de hacer ciencia, a lo más que podemos aspirar es a una castrante reificación de sus propuestas.

Bibliografía

Amundson, R. (2005), The Changing Role of the Embryo in Evolutionary thought: Roots of Evo-Devo, Cambridge: Cambridge University Press.

Annunziata, R., Perillo, M., Andrikou, C., Cole, A., Martinez, P. y M. Arnone (2014), "Pattern and Process During Sea Urchin Gut Morphogenesis: The Regulatory Landscape”, Genesis 52(3): 251-268.

Arnoult, L., Su, K., Manoel, D., Minervino, C., Magriña, J., Gompel, N. y B. Prud'homme (2013), "Emergence and Diversification of Fly Pigmentation through Evolution of a Gene Regulatory Module”, Science 339(6126): 1423. 1426.

Arthur, W. (2000), “The Concept of Developmental Reprogramming and the Quest for an Inclusive Theory of Evolutionary Mechanisms", Evolution $\mathcal{E}$ Development 2(1):49-57.

Bavister, B.D. y J.M. Squirrell (2000), "Mitochondrial Distribution and Function in Oocytes and Early Embryos", Human Reproduction 15(2): 189-198.

Bertalanffy, L. (1972), “The History and Status of General Systems Theory”, The Academy of Management Journal 15: 407-426.

Bianchi-Frias, D., Orian, A., Delrow, J., Vazquez, J., Rosales-Nieves, A. y S. Parkhurst (2004), "Hairy Transcriptional Repression Targets and Cofactor Recruitment in Drosophila”, Public Library of Science Biology 2(7): e178.

Bonner, J.T. (ed.) (1982), Evolution and Development. Report of the Dahlem Workshop on Evolution and Development, BerlinHeidelberg-New York: Springer.

Bonner, J.T. (1955), Cells and Societies, Princeton: Princeton University Press.

Brigandt, I. (2007), “Typology Now: Homology and Developmental Constraints Explain Evolvability”, Biology E⿱ Philosophy 22(5): 709-725.

Callebaut, W., Müller, G.B. y S.A. Newman (2007), "The Organismic Systems Approach: Evo-Devo and the Streamlining of the Saturalistic Agenda”, en Sansom, R. y R.N. Brandon (eds.) (2007), Integrating Evolution and Development: From Theory to Practice, Cambridge: MIT Press pp. 25-92.

Caltech Archives (2009/2011), The Drosophila Drawings of Edith M. Wallace, recuperado el 30 de marzo de 2015 de http://archives.caltech.edu/news/wallace.html

Carroll, S.B. (2008), "Evo-Devo and an Expanding Evolutionary Synthesis: A Genetic Theory of Morphological Evolution”, Cell 134(1): 25-36.

Casanueva, M. (2010), "Qué es la Biología”, en Pérez Tamayo, R. (coord.), Discusiones sobre la vida y la biología, 
Cuadernos del Seminario de Problemas Científicos y Filosóficos, México: Siglo XXI-UNAM, pp. 41-78.

Casanueva, M., Folguera G. y M. Peimbert (2013), "Jerarquías integración y complejidad en biología, un posible marco para la evo-devo”, Contrastes. Suplemento 18: 127-142.

Casanueva, M. y M. Martínez (2014), “Marcos causales y síntesis teóricas en biología”, Acta Scientiae Canoas 16(2): $330-$ 344.

Conklin, E. (1905), “The Organization and Cell Lineage of the Ascidian Egg”, Journal of the Academy of Natural Sciences 13: 1-119.

Crow, J.F. (2008), “Commentary: Haldane and Beanbag Genetics”, International Journal of Epidemiology 37(3): $442-445$.

de Beer, G.R. (1940), Embryos and Ancestors, Oxford: Clarendon Press.

Della, P., Souer, E. y R. Koes (2014), “Arguments in the Evo-Devo Debate: Say it with Flowers!”, Journal of Experimental Botany 65(9): 2231-2242.

Emmeche, C., Køppe, S. y F. Stjernfelt (1997), “Explaining Emergence: 'Towards an Ontology of Levels'”, Journal for General Philosophy of Science 28: 83-119.

Filion, G., van Bemmel, J., Braunschweig, U., Talhout, W., Kind, J., Ward, L., Brugman, W., de Castro, I., Kerkhoven, R., Bussemaker, H. y B. van Steensel (2010), "Systematic Protein Location Mapping Reveals Five Principal Chromatin Types in Drosophila Cells”, Cell 143(2): 212-224.

Fischer, A.H. y J. Smith (2012), "Evo-Devo in the Era of Gene Regulatory Networks", Integrative and Comparative Biology 52(6): 842-849.

Fujii, S., Nishio, T. y H. Nishida (2008), “Cleavage Pattern, Gastrulation, and Neurulation in the Appendicularian, Oikopleura dioica", Development Genes and Evolution 218: 69-79.

Gazave, E., Lapébie, P., Richards, G., Brunet, F., Ereskovsky, A., Degnan, B., Borchiellini, C., Vervoort, M. y E. Renard (2009), "Origin and Evolution of the Notch Signaling Pathway: An Overview from Eukaryotic Genomes", BioMed Central Evolutionary Biology 9(1): 249.

Gehring, W.J. (1985), “The Homeobox: A Key to the Understanding of Development?”, Cell 40: 3-5.

Gerson, E.M. (2015), “The Interaction of Research Systems in the Evo-Devo Juncture”, en Love, A.C. (ed.) (2015), Conceptual Change in Biology: Scientific and Philosophical Perspectives on Evolution and Development, Berlin: Springer, pp. 441-457.

Gilbert, S.F. (2000), “Diachronic Biology Meets Evo-Devo: C.H. Waddington's Approach to Evolutionary Developmental Biology”, American Zoologist 40(5): 729-737.

Gilbert, S.F. (2003a), “Evo-Devo, Devo-Evo, and Devgen-Popgen”, Biology and Philosophy 18(2): 347-352.

Gilbert, S.F. (2003b), “The Morphogenesis of Evolutionary Developmental Biology”, International Journal of Developmental Biology 47, 467-477.

Gilbert, S.F. (2009), The Adequacy of Model Systems for Evo-Devo: Modeling the Formation of Organisms/Modeling the Formation of Society, Netherlands: Springer.

Gilbert, S.F. (2013), A Companion to Developmental Biology, Sutherland: Sinaeur and Assoc. (También disponible en http://10e.devbio.com/. Las imágenes de Conklin fueron consultadas el 30 de marzo de 2015 en: http://10e.devbio.com/article.php?ch=1\&id=3.)

Gould, S.J. (1977), Ontogeny and Phylogeny, Cambridge: The Belknap Press of Harvard University Press.

Gould, S.J. (1990), Wonderful Life: the Burguess Shale and the Nature of History, New York: W.W. Norton \& Company.

Hall, B.K. (2003), “Evo-Devo: Evolutionary Developmental Mechanisms”, International Journal of Developmental Biology 47(7/8): 491-496.

Hall, B.K. y W.M. Olson (2003), Keywords and Concepts in Evolutionary Developmental Biology, Cambridge: Harvard University Press.

Hamburger, V. y H.L. Hamilton (1951), “A Series of Normal Stages in the Development of the Chick Embryo”, Journal of Morphology 88(1): 49-92.

Hendrikse, J.L., Parsons, T.E. y B. Hallgrímsson (2007), "Evolvability as the Proper Focus of Evolutionary 
Developmental Biology", Evolution Eु Development 9(4): 393-401.

Hoßfeld, U. y L. Olsson (2003), “The Road from Haeckel: The Jena Tradition in Evolutionary Morphology and the Origins of 'Evo-Devo'”, Biology Eु Philosophy 18(2): 285-307.

Houliston, E., Pickering, S.J. y B. Maro (1987), "Redistribution of Microtubules and Pericentriolar Material During the Development of Polarity in Mouse Blastomeres", The Journal of Cell Biology 104(5): 1299-1308.

Jablonka, E. y M.J. Lamb (2005/2014), Evolution in Four Dimensions: Genetic, Epigenetic, Behavioral, and Symbolic Variation in the History of Life, Cambridge: MIT press.

Keller, E.F. (2000), "Models of and Models for: Theory and Practice in Contemporary Biology", Philosophy of Science 67: S72-S86.

Keller, E.F. (2002), “Language in Action: Genes and the Metaphor of Reading”, en Dörries, M. (ed.), Experimenting in Tongues: Studies in Science and Language, California: Stanford University Press, pp. 76-88.

Kitchen, J.L. y R.G. Allaby (2013), "Systems Modeling at Multiple Levels of Regulation: Linking Systems and Genetic Networks to Spatially Explicit Plant Populations”, Plants 2(1): 16-49.

Krisher, R.L., Schoolcraft, W.B. y M.G. Katz-Jaffe (2015), "Omics as a Window to View Embryo Viability”, Fertility and Sterility 103(2): 333-341.

Lakoff, G. y M. Johnson (1980/2003), Metaphors We Live By, Chicago: University of Chicago Press.

Lakoff, G y M. Johnson (1999), Philosophy in the Flesh: The Embodied Mind and its Challenge to Western Thought, New York: Basic Books.

Lakoff, G. y R.E. Núñez (2000), Where Mathematics comes from: How the Embodied Mind Brings Mathematics into Being, New York: Basic books.

Laland, K.N., Odling-Smee, J. y S.F. Gilbert (2008), “Evo-Devo and Niche Construction: Building Bridges”, Journal of Experimental Zoology Part B: Molecular and Developmental Evolution 310(7): 549-566.

Laland, K.N., Sterelny, K., Odling-Smee, J., Hoppitt, W. y T. Uller (2011), "Cause and Effect in Biology Revisited: Is Mayr's Proximate-Ultimate Dichotomy still Useful?”, Science 334(6062): 1512-1516.

Laland, K., Uller, T., Feldman, M., Sterelny, K., Müller, G.B., Moczek, A. y J.E. Strassmann (2014), "Does Evolutionary Theory Need a Rethink?”, Nature 514(7521):161-164.

Laubichler, M.D. (2010), "Evolutionary Developmental Biology offers a Significant Challenge to the Neo-Darwinian Paradigm”, en Ayala, F.J. y R. Arp (eds.), Contemporary Debates in Philosophy of Biology, Sussex, U.K.: John Wiley \& Sons, pp. 199-212.

Laubichler, M.D. y J. Maienschein (eds.) (2007), From Embryology to Evo-Devo: A History of Developmental Evolution, Cambridge, MA: MIT Press.

Leung, M. (2004), Chicken Embryo, recuperado el 30 de marzo de 2015 de http://www.microscopyuk.org.uk/mag/artnov04macro/mlchicken.html, Fotografías del embrión de pollo en cámara de agua.

Lewis, E.B. (1978), “A Gene Complex Controlling Segmentation in Drosophila”, Nature 276: 565-570.

Longabaugh, W.J. (2012), "BioTapestry: A Tool to Visualize the Dynamic Properties of Gene Regulatory Networks", Gene Regulatory Networks, New York: Humana Press, Springer.

Love, A.C. (2015a), "Evolutionary Developmental Biology: Philosophical Issues”, en Huneman, P. y M. Silberstein (eds.), Handbook of Evolutionary Thinking in the Sciences, Netherlands: Springer, pp. 265-283.

Love, A.C. (2015b), Conceptual Change and Evolutionary Developmental Biology, Berlin: Springer.

Love, A.C. y R.A. Raff (2003), "Knowing your Ancestors: Themes in the History of Evo-Devo", Evolution E⿱ Development 5(4): 327-330.

Maro, B., Johnson, M.H., Pickering, S.J. y D. Louvard (1985), "Changes in the Distribution of Membranous Organelles During Mouse Early Development”, Journal of Embryology and Experimental Morphology 90(1): 287-309.

Martínez, M. y M. Esposito (2014), "Multilevel Causation and the Extended Synthesis”, Biological Theory 9(2): $209-220$.

Mayr, E. (1959), “Where Are We?”, Cold Spring Harbor Symposia on Quantitative Biology 24: 1-14.

Minelli, A. y J. Baedke (2014), "Model Organisms in Evo-Devo: Promises and Pitfalls of the Comparative Approach", 
History and Philosophy of the Life Sciences 36(1): 42-59.

Morgan, T.H. (1917), “The Theory of the Gene”, American Naturalist 51: 513-544.

Mormino, K.S. (2011), Chicken Embryo Development, recuperado el 30 de marzo de 2015 de http://www.the-chickenchick.com/2011_04_01_archive.html.

Moulines, C.U. (1994), “Qué clases de cosas hay?”, en Gómez Pín, V. (comp.), Categorías e inteligibilidad global (Actas del Primer Congreso Internacional de Ontología), Bellaterra: Universitat Autònoma de Barcelona, pp. 25-33.

Müller, G.B. (2007), “Evo-Devo: Extending the Evolutionary Synthesis”, Nature Reviews Genetics 8(12): 943-949.

Müller, G.B. (2014), “Evo-Devo Shapes the Extended Synthesis”, Biological Theory 9(2): 119-121.

Neurath, O. (1932), "Protocol Statements", en Ayer, A. (ed.) (1959), Logical Positivism, New York: Free Press. (Traducción castellana: El Positivismo Lógico, México: Fondo de Cultura Económica, 1978, pp. 260-261.)

Nishida, H. (2008), “Development of the Appendicularian: Culture, Genome, and Cell Lineages", Development, Growth $\mathcal{E}$ Differentiation 50: S239-S256.

Noble, D. (2006), The Music of Life: Biology Beyond Genes, Oxford: Oxford University Press.

Noble, D. (2015), “Evolution Beyond Neo-Darwinism: A New Conceptual Framework”, The Journal of Experimental Biology 218(1): 7-13.

Odling-Smee, F.J., Laland, K.N. y M.W. Feldman (2003), Niche Construction: The Neglected Process in Evolution, Princeton: Princeton University Press.

Pick, L. y A. Heffer (2012), "Hox Gene Evolution: Multiple Mechanisms Contributing to Evolutionary Novelties”, Annals of the New York Academy of Sciences 1256(1): 15-32.

Pigliucci, M. (2009), “An Extended Synthesis for Evolutionary Biology”, Annals of the New York Academy of Sciences 1168(1): 218-228.

Pigliucci, M. y G. Muller (2010), “Elements of an Extended Evolutionary Synthesis”, en Pigliucci, M. y G.B. Müller (eds.), Evolution: The Extended Synthesis, Cambridge, MA: MIT Press, pp. 1-17.

Plutynski, A. (2008), "Explaining how and Explaining Why: Developmental and Evolutionary Explanations of Dominance”, Biology E⿱ Philosophy 23(3): 363-381.

Polutry CRC (2006), Chicken Embryo Development, recuperado el 30 de marzo de 2015 de http://www.poultryhub.org/embryo/.

Prud'homme, B., Minervino, C., Hocine, M., Cande, J., Aouane, A., Dufour, H., Kassner, V. y N. Gompel (2011), "Body Plan Innovation in Treehoppers Through the Evolution of an Extra Wing-Like Appendage", Nature 473(7345): 83-86.

Prud'homme, B. (2013), Evolution and Development of Morphology and Behavior, recuperado el 30 de marzo de 2015 de http://www.ibdm.univ-mrs.fr/equipe/evolution-and-development-of-morphology-and-behavior

Putnam, H. (1981), Reason, Truth and History, Cambridge: University Press.

Raff, R.A. (2000), “Evo-Devo: the Evolution of a New Discipline”, Nature Reviews Genetics 1(1): 74-79.

Robert, J.S. (2002), “How Developmental is Evolutionary Developmental Biology?”, Biology EF Philosophy 17(5): 591 611.

Sakkas, D., Katz-Jaffe, M.G. y C.E. Sueldo (2014), Gamete and Embryo Selection: Genomics, Metabolomics and Morphological Assessment, Dordrecht: Springer.

Saudemont, A., Haillot, E., Mekpoh, F., Bessodes, N., Quirin, M., Lapraz, F., Duboc, V., Röttinger, E., Range, R., Oisel, A., Besnardeau, L., Wincker, P. y T. Lepage (2010), "Ancestral Regulatory Circuits Governing Ectoderm Patterning Downstream of Nodal and BMP2/4 Revealed by Gene Regulatory Network Analysis in an Echinoderm", Public Library of Science Genetic 6(12): e1001259.

Sethi, A.J., Wikramanayake, R.M., Angerer, R.C., Range, R.C. y L.M. Angerer (2012), "Sequential Signaling Crosstalk Regulates Endomesoderm Segregation in Sea Urchin Embryos”, Science 335(6068): 590-593.

Sturtevant, A.H. (1921), “Genetic Studies on Drosophila Simulans. II. Sex-linked Group of Genes”, Genetics 6(1): 43.

Swalla, B.J. (2006), “Building Divergent Body Plans with Similar Genetic Pathways”, Heredity 97(3): 235-243. 
Weiss, P.A. (1950), "Perspectives in the Field of Morphogenesis", Quarterly Review of Biology 25: 177-198.

Winther, R.G. (2015), Evo-Devo As a Trading Zone, Netherlands: Springer. 